\title{
6-Mercaptopurine metabolism in Crohn's disease: correlation with efficacy and toxicity
}

\author{
C Cuffari, Y Théorêt, S Latour, G Seidman
}

\begin{abstract}
Background-6-Mercaptopurine (6-MP) has confirmed short and longterm efficacy in the treatment of IBD. However, the relation between its metabolism, efficacy, and side effects is not well understood.

Aims-To assay 6-MP metabolites and to correlate levels with drug compliance, disease activity, and adverse effects of treatment.

Patients-Heparinised blood was obtained prior to daily administration of 6-MP in 25 adolescent Crohn's disease patients (14 ileocolitis, 11 colitis) receiving $1 \cdot 2$ (range 0.4-1.6) $\mathrm{mg} / \mathrm{kg} / \mathrm{day}$ for a mean of 17 (range 4-65) months.
\end{abstract}

Methods-Erythrocyte free bases 6-thioguanine (6-TG) and 6-methyl-mercaptopurine (6-MMP) were measured (pmol $8 \times 10^{8}$ red blood cells) using reverse phase high performance liquid chromatography. Results-Disease activity (modified Harvey-Bradshaw index) improved significantly with 6-MP $(p=0 \cdot 001)$. Clinical remission was achieved in $72 \%$ of patients, who stopped taking prednisone, or were successfully weaned to a low alternate day dose $(<0.4 \mathrm{mg} / \mathrm{kg} / \mathrm{OD})$. Remission correlated well with erythrocyte 6-TG $(p<0.05)$, but not 6-MMP levels. Neutropenia was associated with $6-\mathrm{MP}$ use $(p<0.005)$, but did not correlate with erythrocyte 6-MP metabolite levels. One patient refractory to 6-MP had 6-TG, but no measureable 6-MMP production, suggesting deficient thiopurine methyl-transferase activity or poor compliance. 6-MP induced complications (hepatitis, pancreatitis, and marrow suppression) were generally associated with increased 6-MMP levels.

Conclusions-These results suggest that high performance liquid chromatography measurement of erythrocyte 6-MP metabolites may provide a quantitative assessment of patient responsiveness and compliance to treatment. The data support an immunosuppressive role for 6-TG, and potential cytotoxicity of raised 6-MMP levels.

(Gut 1996; 39: 401-406)

Keywords: inflammatory bowel disease, 6-mercaptopurine, metabolism, high performance liquid chromatography.

6-Mercaptopurine (6-MP) and its parent drug azathioprine are well known for their immunosuppressive and lymphocytotoxic properties. ${ }^{1}$ Consequently, these drugs are increasingly used in the treatment of corticosteroid dependent inflammatory bowel disease (IBD)..$^{12}$ 6-MP eliminates the need for corticosteroids in about $75 \%$ of patients, with a median response time of three to four months. ${ }^{3}{ }^{4}$ Furthermore, when combined with prednisone, azathioprine has recently been shown to induce remission faster, more frequently, and at a lower corticosteroid dose than prednisone alone. ${ }^{3}$ These immunosuppressants have also been shown to improve Crohn's disease patients' quality of life by decreasing symptoms from their perianal disease. ${ }^{4}$ However, potential complications of treatment exist, including allergic reactions, neoplasia, superinfections, hepatitis, bone marrow suppression, and pancreatitis. ${ }^{1}$ Furthermore, not all patients respond favourably, raising the possibility that altered drug metabolism or patient compliance affect efficacy and toxicity. ${ }^{3-7}$

The immunosuppressive properties of 6-MP and azathioprine are most probably mediated via their interference with protein synthesis and nucleic acid metabolism in the sequence that follows antigen stimulation, as well as by their cytotoxic effects on lymphoid cells. ${ }^{89}$ This direct cytotoxicity against lymphoid cells is the basis for their use in the treatment of lymphoma and leukaemia. ${ }^{10}$ As $6-\mathrm{MP}$ is not active, it must be transformed intracellularly into a ribonucleotide, which functions as a purine antagonist. However, 6-MP undergoes rapid and extensive catabolic oxidation to 6-thiouric acid in the intestinal mucosa and liver by the enzyme xanthine oxidase (Fig 1). ${ }^{9}$ As proof, the absolute bioavailability of 6-MP ranges from $5-37 \% .{ }^{11}$ The anabolic transformation of 6-MP into active metabolites occurs intracellularly along the competing routes catalysed by thiopurine methyl-transferase (TPMT) and hypoxanthine phosphoribosyl transferase (HPRT), giving rise to 6-methylmercaptopurine (6-MMP), 6-methyl-thioinosine 5'-monophosphate (6-Me-tIMP), and 6-thioguanine nucleotides (6-TG), respectively (Fig 1).

An apparent genetic polymorphism has been observed in TPMT activity. Negligible activity was noted in $0.3 \%$, and low activities in $11 \%$ of subjects. ${ }^{12}{ }^{13}$ Indeed, low TPMT activity has been associated with increased cytotoxicity, by allowing 6-MP metabolism to be shunted towards the excessive production of 6-TG nucleotides. ${ }^{13}$ To date however, no studies have examined 6-MP metabolism in IBD patients to correlate dose responsiveness to outcome and toxicity. In view of recent reports showing a low, but non-negligeable incidence of toxicity with these drugs in IBD patients, ${ }^{1}$ we hypothesised that altered TPMT activity may 
<smiles>[O+]c1nc2c(S)nc(O)nc2nc1O</smiles>

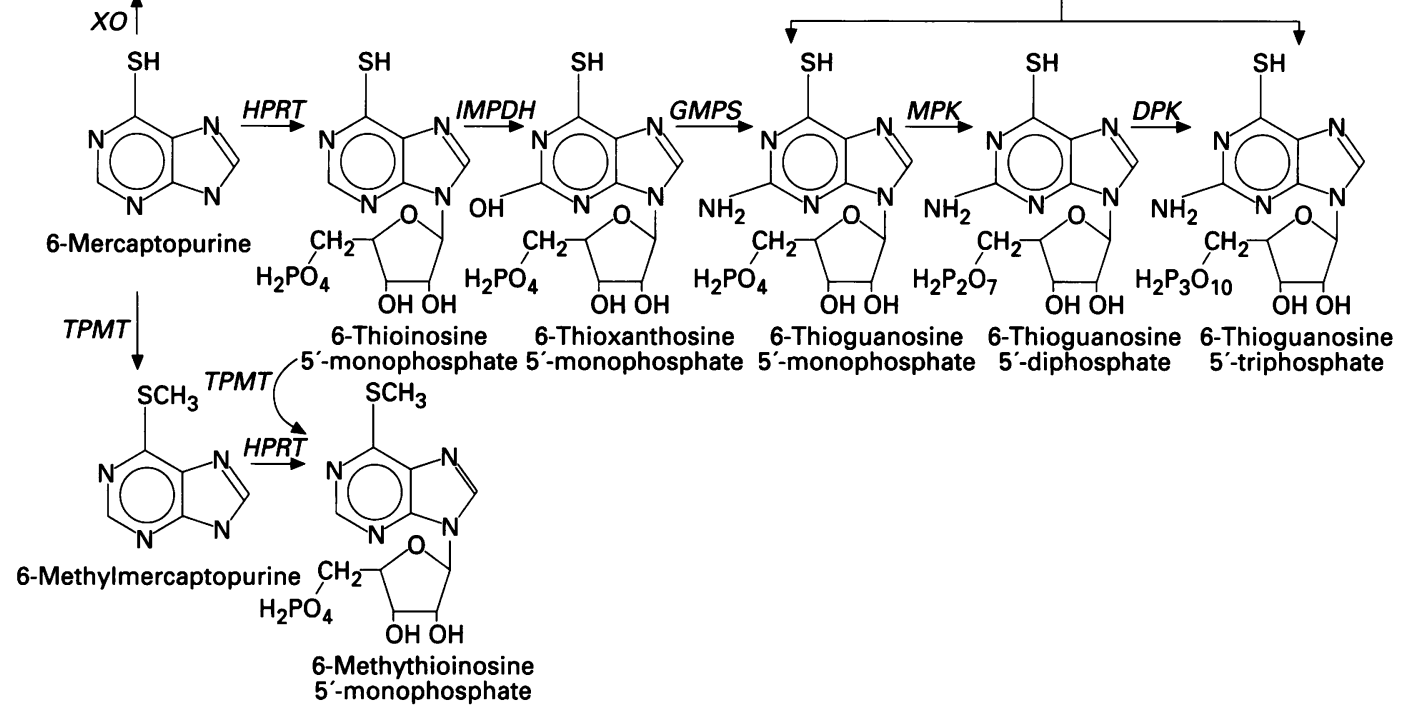

The initial metabolism of $6 M P$ occurs along the competing routes catalysed by thiopurine methyl-transferase (TPMT), xanthine oxidase (XO), and hypoxanthine phosphoribosyltransferase (HPRT). Further metabolism of the thionucleotide is catalysed by inosine monophosphate dehydrogenase (IMPDH) and guanosine monophosphate synthetase (GMPS). The di-and triphosphates are formed by their respective monophosphate (MPK) and diphosphate (DPK) kinases.

explain the refractoriness or toxicity, or both, to 6-MP or azathioprine. The aim of this study was therefore to assay the 6-MP metabolites 6-TG and 6-MMP, and to correlate their intracellular levels with drug efficacy and toxicity.

\section{Methods}

Patients

Adolescent Crohn's disease patients receiving longterm treatment with 6-MP (>4 months) followed up at the paediatric IBD Clinic at Ste Justine's Hospital were recruited for study. Entry criteria included Crohn's disease established by standard clinical, radiological, and histological findings and corticosteroid dependent or refractory disease. ${ }^{1}$ At the time of study entry, the attending paediatric gastroenterologist performed a complete history and physical examination. Data were collected to complete a modified Harvey-Bradshaw index (HBI) of disease activity, ${ }^{14}$ as follows: (a) presence of constitutional signs (anorexia, fatigue, fever (score 1 per item)); (b) abdominal pain ( 1 =mild, $2=$ =moderate, $3=$ =severe); (c) abdominal mass (1=dubious, $2=$ definite, $3=$ definite and tender); (d) stool pattern (number of liquid stools $>3 /$ day, presence of urgency, tenesmus or blood (score 1 per item)), and (e) complications (articular, cutaneous, erythema nodosum, aphthous ulcers, pyoderma gangrenosum), ophthalmological, (uveitis), presence of fistula, abscess or fissure (score 1 per item). The maximum score obtainable was 20 .

For the purposes of this study, successful remission with 6-MP was defined as an $\mathrm{HBI}$ of less than 5 , in patients who were stable without corticosteroids, or weaned to a low dose of prednisone $(\leq 0.4 \mathrm{mg} / \mathrm{kg} / \mathrm{OD})$. An HBI less than 5 correlates with a paediatric Crohn's disease activity index (P-CDAI) below 150, considered quiescent disease. ${ }^{14-16}$ The duration, dosage, and side effects of 6-MP were recorded for each patient undergoing 6-MP metabolite measurement. Each patient's HBI and laboratory date (white blood cell, haemoglobin, and serum albumin) were recorded and compared before and with 6-MP treatment. Drug related side effects were compared with respect to individual metabolite levels. As well, all concurrent medications were tabulated at the time of the patients' visit to clinic. Patients with 6-MP related complications had 6-MP metabolite levels measured in clinic prior to discontinuing 6-MP treatment. Informed consent was obtained prior to study entry.

\section{Blood sampling}

Heparinised blood samples $(5-10 \mathrm{ml})$ were obtained immediately prior to the daily administration of 6-MP, so as to measure predose drug metabolite activities. After washing with phosphate buffered saline, red blood cells were centrifuged (1000 $\mathrm{g}, 5 \mathrm{~min})$ and their numbers were determined from an aliquot. The packed red blood cells were frozen at $-20^{\circ} \mathrm{C}$ until assayed.

\section{6-MP metabolite assay}

The determination of red blood cell free thiopurines 6-TG, 6-MP, and 6-MMP was based on a slight modification of a reversed phase high performance liquid chromatography assay developed by Lennard and Singleton. ${ }^{17}$ In this assay, the nucleoside and nucleotide mono-, 
di-, and triphosphate moieties are hydrolysed back to their respective thiobases. Briefly, thawed red blood cells were mixed well, and a $100 \mu \mathrm{l}$ aliquot was added to $500 \mu \mathrm{l}$ water and $300 \mu \mathrm{l} \mathrm{DL}$ - dithiotreitol $(10 \mathrm{mM})$. To this was added $500 \mu$ l sulphuric acid (1.5 M), and the tubes were heated at $100^{\circ} \mathrm{C}$ for three hours in a dry bath incubator (Fisher Scientific). After cooling, $500 \mu \mathrm{l}$ of 3.4 sodium hydroxide was added, followed by $4 \mathrm{ml}$ of $1 \mathrm{mM}$ phenylmercuric chloride in methylene chloride. After gentle shaking for 10 minutes and centrifugation, the organic layer was back extracted with $200 \mu \mathrm{l}$ of $0 \cdot 1 \mathrm{~N}$ hydrochloric acid. For 6-TG and 6-MP determination, $100 \mu \mathrm{l}$ of the acidic extract was injected through a 506 autosampler (Beckman) onto a Waters NovaPak $\mathrm{C}_{18}$ column $(3.9 \times 150 \mathrm{~mm})$. The analytical column was protected by an in line filter $(0.45$ $\mu \mathrm{m}, \mathrm{SSI})$. The parent $6-\mathrm{TG}$ and 6-MP were detected using a programmable detector module 166 (Beckman) set at $342 \mathrm{~nm}$ and the chromatographic traces were stored on a microcomputer for further analysis using System Gold software (Beckman). A Model 126 programmable solvent module (Beckman) was used for solvent delivery. The mobile phase consisted of water containing $50 \mathrm{mM}$ orthophosphoric and $0.5 \mathrm{mM}$ DL-dithiotreitol. For 6-MMP determination, $50 \mu$ l of the acidic extract was processed as indicated above with the following modifications: the wavelength was set at $314 \mathrm{~nm}$, the mobile phase of methanol:water $(4: 96, \mathrm{v} / \mathrm{v})$ contained $150 \mathrm{mM}$ triethylamine and $0.5 \mathrm{mM}$ DL-dithiotreitol, and was adjusted to $\mathrm{pH} 3.2$ with orthophosphoric acid. Under these conditions, the percentage of recovery for 6-TG or 6-MP was over $85 \%$, with a coefficient of variation of less than $10 \%$. Calibration curves were linear with correlation coefficients of 0.998 for $6-\mathrm{TG}$ and 0.999 for 6-MP and 6-MMP. The limit of quantification was $35 \mathrm{pmol} / 8 \times 10^{8} \mathrm{red}$ blood cells for $6-\mathrm{TG}$, and $50 \mathrm{pmol} / 8 \times 10^{8}$ red blood cells for 6-MMP. The reproducibility of the assay was evaluated by the intra-assay coefficient of variation, which was less than $4 \%$.

\section{Statistical methods}

Non-parametric statistical analyses comparing 6-MP metabolite values to the patients' respective HBI of disease activity were performed using the Spearman rank correlation coefficient. HBI of disease activity and corticosteroid dose before and with $6 \mathrm{MP}$ treatment were compared with the Sign test. Laboratory data (white blood cell, haemoglobin, and serum albumin) were compared before and with 6-MP treatment by the paired Student $t$ test. $\chi^{2}$ Analysis was used to find out if concomitant drug treatment influenced 6-MP metabolite activities.

\section{Results}

\section{Patient outcome}

The 25 adolescent Crohn's disease patients had a mean age of $15 \cdot 8$ years (range 9-19).
Analysis of 6-MP metabolites was performed once the assay was established and validated, at the time of a clinic visit with other routine blood testing. They had received an average of $1.2 \mathrm{mg} / \mathrm{kg} /$ day of $6-\mathrm{MP}$ (range $0 \cdot 4-1 \cdot 6$ ) for a mean of 17 months (range 4-65). Ileocolitis was present in 14, and colitis in 11 patients. Overall, remission was achieved in $72 \%$ of patients taking 6-MP, when analysed on an intent to treat basis. This included $71 \%$ and $73 \%$ of patients with ileocolitis and colitis, respectively. A criteria of successful remission in this study included the tapering of prednisone to $\leq 0.4 \mathrm{mg} / \mathrm{kg} / \mathrm{OD}$.

The HBI of disease activity improved significantly ( $p=0.001)$ with the use of 6-MP (Fig 2). A significant reduction in corticosteroid dose was accomplished, from a mean of 0.53 to 0.20 $\mathrm{mg} / \mathrm{kg} /$ day, $(\mathrm{p}<0.01)$. A comparison of before and with 6-MP haemoglobin (119.4 (2.9), $123.9(4.3) \mathrm{g} / \mathrm{l})$ and serum albumin $(40.3$ $(1 \cdot 5) .40 \cdot 7(0 \cdot 8) \mathrm{g} / \mathrm{l})$ values did not show any significant changes.

Disease activity and 6-MP metabolite values

Native 6-MP was detectable in just three patients, and only in negligible quantities. Median erythrocyte 6-TG and 6-MMP levels ( $\mathrm{pmol} / 8 \times 10^{8}$ red blood cells (range)) were 254 (64-1038) and $3486(0-16312)$, respectively. 6-TG values did not correlate with 6-MMP levels, as measured by the Spearman rank correlation coefficient, (Fig 3). In 15 patients, serial 6-TG activities were measured on the same dose of 6-MP, after a delay of 2-24 months. Initial median (range) 6-TG levels (326 (126-452)) showed no significant variability when compared with follow up (263 (131-465)). Patients receiving sulphasalazine or related salicylates (5-ASA) did not show 6 -TG levels significantly above the median $\left(\chi^{2}\right.$ analysis, data not shown).

Erythrocyte 6-TG levels showed a significant $(p<0 \cdot 05)$ inverse correlation with the HBI of disease activity (Fig 4). On the other hand, values of 6-MMP did not correlate significantly with the HBI. However, the patient with the highest index of disease activity had undetectable levels of 6-MMP. A 6-MMP level of zero in a patient who is taking the drug, as confirmed by measureable 6-TG levels (Fig 3),

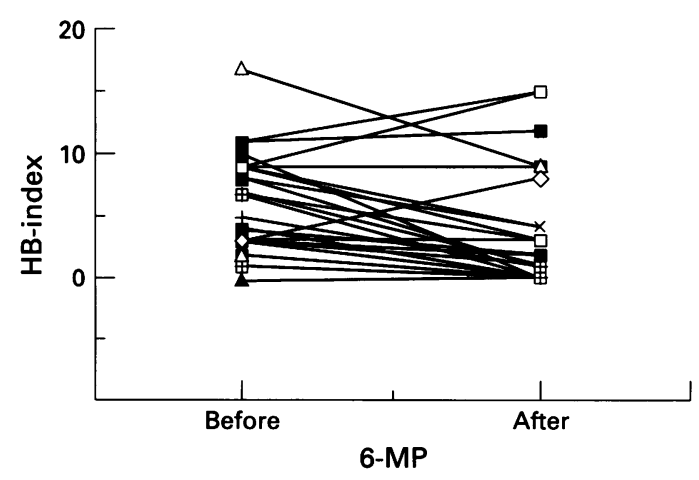

Figure 2: The effect of 6-MP treatment on disease activity in 25 paediatric IBD patients, as measured by the modified Harvey Bradshaw index. The $H B$ index decreased significantly with 6-MP treatment ( $p=0.001$, Sign test). 


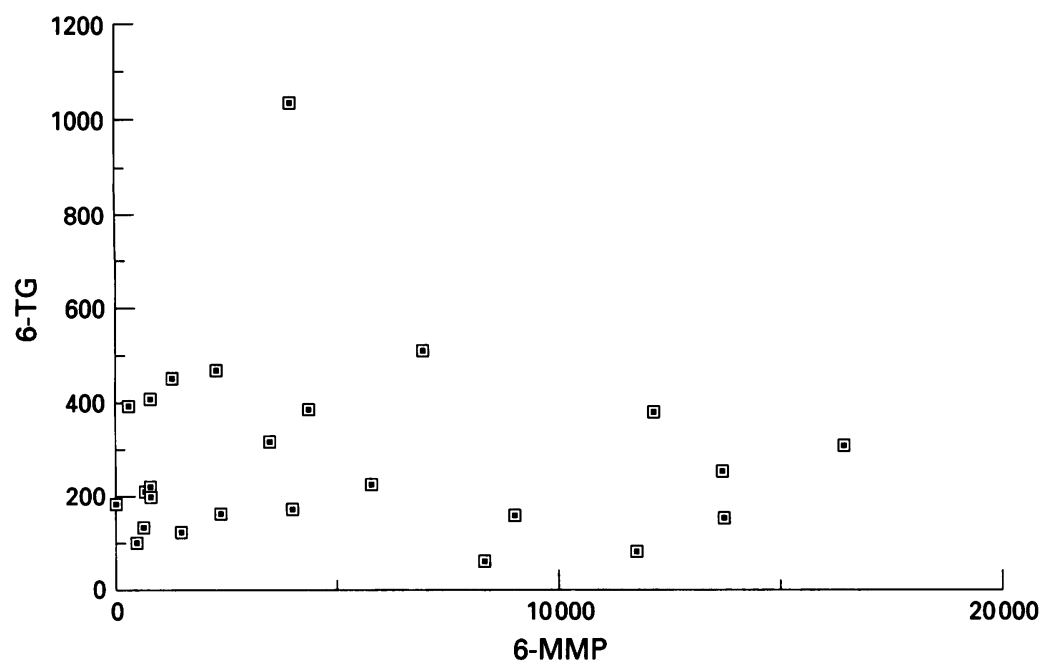

Figure 3: Correlation between erythrocyte 6-TG and 6-MMP levels. Erythrocyte 6-TG (64-1038 pmol/8 $\times 10^{8}$ red blood cells (range)) did not correlate with 6-MMP values (range 0-16312 pmol/8 $\times 10^{8}$ red blood cells) as measured by the Spearman rank correlation coefficient.

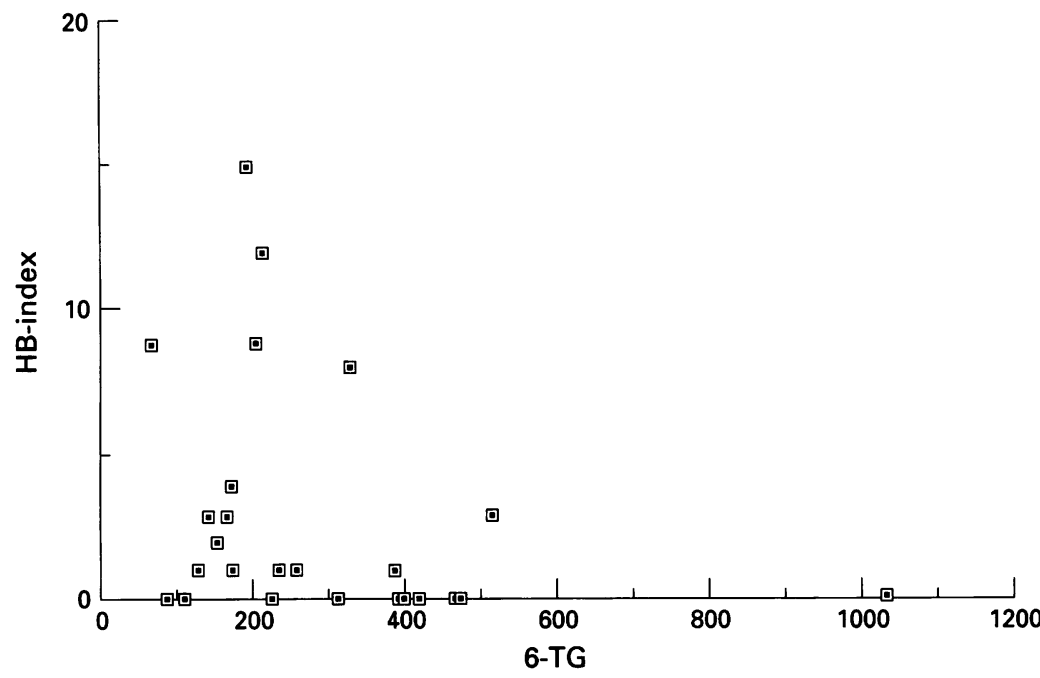

Figure 4: Correlation between IBD disease activity (modified $H B$ index) and pre-dose erythrocyte 6-TG metabolite levels ( $p$ mol/8 $\times 10^{8}$ red blood cells). The HB index correlated inversely with 6-TG values, as measured by the Spearman rank correlation coefficient $(\mathrm{r}=-0.457, p<0.05)$. had pancreatitis, three of whom were confirmed biochemically before onset of symptoms, by routine screening. Serum amylase and lipase were greater than twice the upper limit of normal. The fourth case had characteristic abdominal pain, and the diagnosis of pancreatitis was confirmed biochemically and sonographically. The one patient with 6-MP induced hepatitis was identified by liver biopsy. One other patient had 6-MP induced pancytopenia.

All but one patient in this group with 6-MP related complications were in clinical remission, as confirmed by their HBI $(<5)$. Interestingly, five of six patients had considerably increased levels of 6-MMP compared with median values, as shown in Table I. In contrast, the lone patient in this group with refractory Crohn's disease had no 6-MMP detectable and 6-TG levels below the median, yet had pancreatitis.

A significant decrease in neutrophil count was seen (Table II) with 6-MP treatment $(p<0.005)$. There were, however, no cases of profound neutropenia $\left(<1000 / \mathrm{mm}^{3}\right)$, nor significant infections. Neutrophil counts with 6-MP treatment did not correlate with individual red blood cell 6-MP metabolite levels (data not shown).

\section{Discussion}

Overall, when analysed on an intent to treat basis, $72 \%$ of our Crohn's disease patients receiving 6-MP treatment successfully achieved disease remission, as defined by a normal HBI while taking no corticosteroids, or weaned to a low, alternate day dose of prednisone $(<0.4 \mathrm{mg} / \mathrm{kg} / \mathrm{OD})$. This rate of remission in corticosteroid dependent Crohn's disease is comparable with that previously reported in other adult ${ }^{1-4}$ and paediatric series. ${ }^{18-20}$ The major aim of this study was to discover if 6-MP metabolite levels correlated with its immunomodulatory effect in a group of patients with IBD. High performance liquid chromatography measurement of erythrocyte 6-MP metabolites showed a significant inverse correlation between 6-TG levels and the HBI of disease activity, thus supporting the immunosuppressive role of its 6-TG metabolites. ${ }^{9}$ The lack of a clinical response (high HBI) was associated with low 6-TG metabolites. However, satisfactory clinical response (low HBI) was associated with a wide range of erythrocyte 6-TG levels. As erythrocyte 6-TG levels represent an indirect measure of bone

Among the 25 cases, six had 6-MP associated side effects $(24 \%)$, as listed in Table I. Four

TABLE I Complications of 6-MP treatment in Crohn's disease patients compared with disease activity, 6-MP dose, and pre-dose erythrocyte metabolite activities

\begin{tabular}{|c|c|c|c|c|c|c|c|}
\hline $\begin{array}{l}\text { Patient number } \\
\text { Disease location }\end{array}$ & $\begin{array}{l}\text { (1) Crohn's } \\
\text { colitis }\end{array}$ & $\begin{array}{l}\text { (2) Crohn's } \\
\text { ileocolitis }\end{array}$ & $\begin{array}{l}\text { (3) Crohn's } \\
\text { colitis }\end{array}$ & $\begin{array}{l}\text { (4) Crohn's } \\
\text { ileocolotis }\end{array}$ & $\begin{array}{l}\text { (5) Crohn's } \\
\text { colitis }\end{array}$ & $\begin{array}{l}\text { (6) Crohn's } \\
\text { colitis }\end{array}$ & $\begin{array}{l}\text { No complication } \\
\text { group }\end{array}$ \\
\hline Complication & Pancreatitis & Pancreatitis & $\begin{array}{l}\text { Bone marrow } \\
\text { suppression }\end{array}$ & Hepatitis & Pancreatitis & Pancreatitis & 0 \\
\hline $\begin{array}{l}\text { HB index } \\
\text { Duration of 6-MP^ } \\
\text { Dose of 6-MP }(\mathrm{mg} / \mathrm{kg} / \mathrm{d}) \\
\text { 6-TG† } \\
\text { 6-MMP† }\end{array}$ & $\begin{array}{c}0 \\
6 \\
1 \cdot 3 \\
266 \\
8177\end{array}$ & $\begin{array}{c}3 \\
13 \\
1 \cdot 5 \\
165 \\
8861\end{array}$ & $\begin{array}{c}0 \\
4 \\
1 \cdot 3 \\
307 \\
16312\end{array}$ & $\begin{aligned} & 0 \\
& 24 \\
& 1 \cdot 2 \\
& 87 \\
& 11651\end{aligned}$ & $\begin{array}{c}2 \\
9 \\
1 \cdot 1 \\
150 \\
13694\end{array}$ & $\begin{array}{c}15 \\
15 \\
0 \cdot 8 \\
191 \\
0\end{array}$ & $\begin{array}{c}1(0-12) \ddagger \\
24 \cdot 7(2-65) \S \\
1 \cdot 2(0 \cdot 4-1 \cdot 6) \oint \\
326(64-1038) \ddagger \\
2213(258-9202) \ddagger\end{array}$ \\
\hline
\end{tabular}

*In months, at time of complication. $\mathrm{tpmol} / 8 \times 10^{8}$ red blood cells measured at the time of complication, before cessation of 6-MP. $\ddagger$ Median data (range). $\$$ Mean data (range) presented for the 19 other IBD patients tolerating 6-MP without adverse effects. 
TABLE II Leucocyte parameters before and after 6-MP treatment in paediatric Crohn's disease

\begin{tabular}{lcll}
\hline Parameter $^{\star}$ & Before 6-MP & After 6-MP & $p$ Value† \\
\hline Total leucocytes & $11.2(0.9)$ & $7.2(0.8)$ & $\mathrm{p}<0.005$ \\
Neutrophils & $8.4(0.7)$ & $5.1(0.8)$ & $\mathrm{p}<0.005$ \\
Lymphocytes & $2.2(0.4)$ & $1.8(0.5)$ & NS \\
\hline
\end{tabular}

${ }^{\star}$ Mean counts $\times 10^{3} / \mathrm{mm}^{3}$. + Paired Student $t$ test.

marrow uptake, it serves to estimate the levels of leucocyte incorporation and thus immunosuppression. The measure of leucocyte 6-TG levels would theoretically allow a stronger correlation to be drawn with clinical responsiveness. Alternatively, as the course of Crohn's disease is extremely variable, we cannot assume that the absence of disease activity is due to the use of 6-MP, despite its known efficacy. ${ }^{2-7}$

In one male adolescent, non-compliance was suspected in view of very low 6-TG levels $(<75)$ on two separate occasions, with a high HBI (>9). Although the patient had initially denied poor compliance, he subsequently confirmed this suspicion when confronted with the pharmacological data. This case illustrates the utility of measuring 6-TG bases (including nucleoside and nucleotide moities) to verify patient compliance to treatment. Further prospective studies are needed to also confirm whether physicians may be able to individually tailor 6-MP dose, to achieve specific therapeutic metabolite ranges.

Median 6-TG levels in IBD patients were slightly lower than those we have seen in children with acute lymphoblastic leukaemia receiving $6-\mathrm{MP}$ either orally $\left(50 \mathrm{mg} / \mathrm{m}^{2} /\right.$ day) for 14 days, or as an intravenous $\left(50 \mathrm{mg} / \mathrm{m}^{2} / \mathrm{h}\right.$ ) 20 hour infusion. ${ }^{21}$ It has been shown that a steady state is achieved after continuous daily administration of 6-MP for more than two months. ${ }^{22}$ In this study, serial measurements of red blood cell 6-TG concentrations performed in 15 Crohn's disease patients, showed no significant variability over time, in contrast with the study by Zimm et al. ${ }^{11}$

6-MMP metabolite levels did not correlate with disease activity, probably because of the wide range of values detected. The large variation seen from the median in 6-MMP level is probably a consequence of the genetic polymorphism of TPMT activity in the population studied, as well as the unequal dose of drug taken by patients. It remains unclear whether intracellular levels of 6-MMP and 6-TG vary accordingly with variations in TPMT activity. Our study did not show a correlation between erythrocyte 6-TG and 6-MMP levels. Similarly, erythrocyte 6-MMP levels did not correlate with 6-TG levels in our leukaemic children receiving maintenance 6-MP treatment, (unpublished data). Interestingly, the patient with the highest index of disease activity had no measureable 6-MMP, with 6-TG levels below the collective group median. As undetectable 6-MMP levels may be indicative of absent or decreased TPMT activity, an increase in her 6-TG levels would have been expected. Indeed, a patient with
TPMT deficiency showed myelosuppression and elevated 6-TG levels even at a much reduced 6-MP dose. ${ }^{23}$ Although the measure of erythrocyte 6-MMP is a sensitive indicator of TPMT activity, the quantitation of genetic polymorphisms in TPMT activity is best identified through direct enzymatic measure of activity. This patient's refractoriness to 6-MP treatment despite 6-TG values near the median observed within the study group raises the possibility of sub-optimal $6-\mathrm{MP}$ dose $(0 \cdot 8$ $\mathrm{mg} / \mathrm{kg} /$ day), non-compliance or an immunosuppressive role for 6-MMP metabolites. The principal transformation product measured by the high performance liquid chromatography technique is likely to be 6-Me-tIMP, a strong inhibitor of phosphoribosyl pyrophosphate amidotransferase, the first enzyme in purine de novo synthesis. ${ }^{24}$ Recent data using the human lymphoblastic $T$ cell line showed that inhibition of de novo purine synthesis by $6-\mathrm{Me}-$ tIMP was a crucial event in the mechanism of 6-MP induced cytotoxicity. ${ }^{25}$ The therapeutic importance of methylated 6-MP metabolites in Crohn's disease requires further study.

Complications of 6-MP treatment were seen in $24 \%$ of our patients, clearly higher than that previously reported in the literature. ${ }^{1}$ This discrepancy is a consequence of a selection bias in the adolescent IBD population studied, as patients suspected of toxicity to 6-MP were preferentially refered for our metabolite assay. Four patients had pancreatitis (only one of whom was symptomatic), one other case each had drug induced hepatitis or bone marrow suppression. The dose of 6-MP used was not different from the group of patients without complications. As noted above, 6-MMP was not detected in one of the four patients with pancreatitis. In contast, the remaining five patients with drug induced complications had very high 6-MMP activities and comparably lower 6-TG levels. Despite these 6-MP related complications, these patients were in clinical remission. Overall, our data support a permissive role for high methylated 6-MP metabolite levels and 6-MP related complications. However, pancreatitis may ensue despite the absence of 6-MMP. A larger sample size will be necessary to draw conclusions about specific metabolites and 6-MP induced complications.

It has been suggested that sulphasalazine and related salicylate compounds have a direct inhibitory effect on TPMT activity, shunting 6-MP metabolism into 6-TG production, thus predisposing patients to cytotoxic 6-TG levels. ${ }^{26}$ It is thus noteworthy that all patients with 6-MP related complications were either taking sulphasalazine or related salicylate compounds. Nevertheless, this group was found to have somewhat lower erythrocyte 6-TG levels. 6-TG levels were not significantly influenced by sulphasalazine nor other salicylates in our study.

As anticipated, neutrophil counts were significantly lower after 6-MP treatment $(p<0.005)$. However, severe neutropenia was not seen, nor were cases of opportunistic infections encountered. Leucopenia has been associated 
with 6-MP treatment and it has been suggested that 6-MP dose be tailored to induce leucopenia to achieve a desired therapeutic effect in Crohn's disease. ${ }^{27}$ The levels of specific 6-MP metabolites measured herein did not correlate significantly with the leucocyte count, in contrast with what has been described in leukaemic patients treated with higher 6-MP doses, where a strong relation has been shown between 6-MP dose, erythrocyte 6-TG nucleotide levels, and neutropenia. ${ }^{28}$ Clearly, the treatment of IBD does not necessitate the same degree of 6-MP induced leucocytotoxicity required in the treatment of leukaemia. Future studies are needed to identify a therapeutic regimen for 6-MP treatment to better delineate excessive cytotoxicity from immunosuppression. The measure of leucocyte 6-TG levels may help improve our understanding of the beneficial leucocytotoxic effects of 6-MP in Crohn's disease.

In conclusion, our data suggest that measurement of erythrocyte 6-MP metabolites can be useful in treating IBD patients, allowing for the assessment of compliance and responsiveness to treatment. As 6-MP has been shown to induce leucopenia, the measurement of 6-MP metabolites (6-TG as well as 6-MMP moieties) in leucocytes may eventually provide further insight towards establishing a mechanism underlying their therapeutic effect. Our recent preliminary investigative efforts to measure 6-TG in leucocytes has shown a correlation between neutrophil 6-TG levels and responsiveness to treatment, as well as drug induced leucopenia. ${ }^{29}$ Further research is needed to identify a therapeutic regimen for 6-MP treatment allowing clinicians to establish a balance between drug responsiveness and toxicity.

Supported by research scholarship awards (YT, EGS) and a Young Clinician-Scientist award (CC) from the Fonds de Recherche en Santé du Québéc, and grants from Biopedia. We thank Ms Diane Lachapelle for secretarial assistance, and the members of the Pediatric Gastroenterology Division of Hôpital Ste-Justine for their collaboration.

1 Present DH, Meltzer SJ, Krumholz MP, Wolke A Korelitz BI. 6-Mercaptopurine in the management of Korelitz Bl. 6-Mercaptopurine in the management of inflammatory bowel disease: Short- and

2 Pearson DC, May GR, Fick GH, Sutherland LR. Azathioprine and 6-mercaptopurine in Crohn's disease: meta-analysis. Ann Intern Med 1995; 122: 132-42.

3 Ewe K, Press AG, Singe CC, Stufler M, Ueberschaer B, Hommel G, Büschenfelde KHMZ. Azathioprine combined with prednisolone or monotheraphy with prednisolone in active Crohn's disease. Gastroenterolog 1993; 105: 367-72.

4 Korelitz BI, Adler DJ, Mendelsohn RA, Sacknoff AL. Longterm experience with 6-mercaptopurine in the treatment of Crohn's disease. Am $\mathcal{f}$ Gastroenterol 1993; 88: 1198-205.

5 Verhave M, Winter HS, Grand RJ. Azathioprine in the treatment of children with inflammatory bowel disease. $\mathcal{F}$ Pediatr 1990; 117: 809-14.
6 O'Brien JJ, Bayless TM, Bayless JA. Use of azathioprine or 6-mercaptopurine in the treatment of Crohn's disease. Gastroenterology 1991; 101: 39-46.

7 Perrault J, Greseth JLM, Tremaine WJ. 6-Mercaptopurine therapy in selected cases of corticosteroid-dependent Crohn's disease. Mayo Clin Proc 1991; 66: 480-4.

8 Brogan $M$, Hiserodt $\mathrm{J}$, Olicer $M$, et al. The effect of 6-mercaptopurine on natural killer cell activities in 6-mercaptopurine on natural killer cell activities

9 Lennard L. The clinical pharmacology of 6-mercaptopurine. Eur f Clin Pharmacol 1992; 43: 329-39.

10 Bostrom B, Erdmann G. Cellular pharmacology of 6-mercaptopurine in acute lymphoblastic leukemia. $\mathrm{Am} \mathcal{F}$ Pediatr Hematol Oncol 1993; 15: 80-6.

11 Zimm S, Collins JM, Riccardi R, O'Neill R, Narang PK, Chabner $\mathrm{B}$, et al. Variable bioavailability of oral mercaptopurine. Is maintenance chemotherapy in acute lymphoblastic leukemia being optimally delivered? $N$ Engl f Med 1983; 308: 1005-9.

12 Lennard L, Gibson BES, Nicole T, Lilleyman JS Congenital thiopurine methyltransferase deficiency and 6-mercaptopurine toxicity during treatment for acute lymphoblastic leukaemia. Arch Dis Child 1993; 69: 577-9.

13 Lennard L, Van Loon JA, Weinshilboum RM. Pharmacogenetics of acute azathioprine toxicity: relationship to thiopurine methyl-transferase genetic polymorphism. Clin Pharmacol Ther 1989; 46: 149-54.

14 Harvey RF, Bradshaw JM. A simple index of Crohn's disease activity. Lancet 1980; i: 514.

15 Belli D, Seidman EG, Bouthillier L, Weber AM, Roy CC Plétincx $M$, et al. Chronic intermittent elemental diet improves growth failure in children with Crohn's disease. Gastroenterology 1988; 94: 603-10.

16 Best WR, Becktel JM, Singleton JW, Kern F Jr. Development of a Crohn's disease activity index. Gastroenterology ment of a Crohn's

17 Lennard L, Singleton HJ. High-performance liquid chromatographic assay of human red blood cell thiopurine methyltransferase activity. $f$ Chrom Biomed App 1994; 661: 25-33.

18 Markowitz J, Daum F. Immunology of inflammatory bowel disease: Summary of the proceedings of the subcommittee on immunosuppressive use in IBD. F Pediatr Gastroenterol Nutr 1991; 12: 411-23.

19 Markowitz J, Grancher K, Mandel F, Mandel F. Immunosuppressive therapy in pediatric inflammatory bowel disease: Results of a survey of the North American Society for Pediatric Gastroenterology and Nutrition. $A m \mathcal{F}$ Gastroenterol 1993; 88: 44-8.

20 Markowitz J, Rosa J, Grancher K, Aiges H, Daum F. Longterm 6-mercaptopurine treatment in adolescents with Crohn's disease. Gastroenterology 1990; 99: 1347-51.

21 Duchesne D, Latours S, Leclerc JM, Sallan SE, Théorêt Y Pharmacokinetics of oral and intravenous 6-Mercaptopurine (6-MP) in childhood acute lymphoblastic leukemia (ALL). Proc Am Soc Clin Oncol 1994; 13: A341.

22 Lennard L, Lilleyman JS. Variable mercaptopurine metabolism and treatment outcome in childhood lymphoblastic leukemia. F Clin Oncol 1989; 7: 1816-23.

23 Evans WE, Horner M, Chu YQ, Kalwinsky D, Roberts WM. Altered mercaptopurine metabolism, toxic effects, and dosage requirements in a thiopurine methyleffects, and dosage requirements in a thiopurine methyl-
transferase deficient child with acute lymphoblastic transferase deficient child with ac
leukemia. F Pediatr 1991; 119: 985-9.

24 Stet EH, De Abreu RA, Bökkerink JPM, Vogels-Mentink TM, Lambooy LHJ, Trijebls FJM, et al. Reversal of 6-mercaptopurine and 6-methyl-mercaptopurine ribonucleoside cytotoxicity by amidoimidazole carboxamide ribonucleoside in Molt F4 human malignan T-lymphoblasts. Biochem Pharmacol 1993; 46: 547-50.

25 Bökkerink JPM, Stet EH, DeAbreu RA, Damen FJM, Hulscher TW, Bakker MAH, et al. 6-Mercaptopurine: cytotoxicity and biochemical pharmacology in human malignant T-lymphoblasts. Biochem Pharmacol 1993; 45: malignant

26 Szumlanski C, Weinshilboum RM. Sulphasalazine inhibition of thiopurinemethyltransferase: possible mechanism for interaction with 6-mercaptopurine. $\mathrm{Br} \mathcal{f} \mathrm{Clin}$ Pharmacol 1995; 39: 456-9.

27 Colonna T, Korelitz BI. The role of leukopenia in the 6-mercaptopurine-induced remission of refractory Crohn's disease. Am $\mathcal{f}$ Gastroenterol 1993; 89: 362-6.

28 Lennard L, Rees CA, Lilleyman JS, Maddocks JL. Childhood leukemia: a relationship between intracellular 6-mercaptopurine metabolites and neutropenia. $\mathrm{Br} f \mathrm{Clin}$ Pharmacol 1993; 16: 359-63.

29 Cuffari C, Seidman E, Theoret Y. 6-mercaptopurine (6-MP) metabolite measurement in IBD patients' neutrophils correlates with drug efficacy. Gastroenterology 1995; 108: A803. 